\title{
Baena en época islámica: fuentes, arqueología, documentos...
}

\author{
Fátima Martín Escudero *
}

\begin{abstract}
RESUMEN
De Baena en época islámica, del análisis de su ubicación, desarrollo o presencia en las fuentes arábigas nos hablan las fuentes escritas. Además poseemos datos proporcionados por las fuentes arqueológicas, los materiales y los conjuntos numismáticos hallados en el término municipal y el análisis de la población dentro de su territorio, la cora de Cabra, su posición administrativa y política, teorías sobre su toponimia. Bayyána, y su devenir histórico. Se concluye con la reproducción del artículo periodístico de Rodrigo Amador de los Ríos "Baena en los días de la dominación musulmana".
\end{abstract}

PALABRAS CLAVE: Al-Andalus, Baena, fuentes escritas y arqueológicas, toponimia.

Baena, población de la campiña cordobesa, en las estribaciones de la sierra Subbética, posee uno de los términos municipales más grandes de la provincia de Córdoba, con unas 22.031 hectáreas de extensión y mayor riqueza arqueológica, lo que no implica mejor estudiada.

De la presencia islámica en dicho término, como de su asentamiento en la localidad tenemos constancia a través de fuentes escritas y materiales: en especial arqueológicas y numismáticas.

\begin{abstract}
Baena in Islarnic times, her ubication, development or presence in arab sources, is known through written sources. We also have data which stem from archaeology, material analysis and coin hoards forund in her territory, her political situation, place-name theories, and historical development. An article by Rodrigo Amador de los Ríos "Baena en los días de la dominación musulmana" (Baena under Islamic rule) is added at the end of the article.
\end{abstract}

KEY WORDS: Al-Andalus, Baena, written and archaeological sources, toponimy.

Pascual Madoz en su descripción de Baena señala que "...en lo antiguo estuvo sobre un cerro rodeado por dos órdenes de murallas, de las cuales la primera contenía la parte principal de la población, Ilamada la Almedina, y la segunda que llegaba hasta las márgenes del río Marbella, abrigaba en su recinto el resto de la villa, pero en el día están dichas murallas destruidas en parte e interrumpidas, de tal modo que por algunos parajes ni aún se conoce que hayan existido..."!

\footnotetext{
* Real Academia de la Historia.

I MADOZ, Pascual: (1987) "Baena", Diccionario Geográfico-estadístico-histórico de España y sus posesiones en Ultramar. Córdoba. Madrid 1845-50. Valladolid. Pp. 40-43.
} 
Francisco Valverde y Perales ${ }^{2}$, celebre personaje local, en su Historia sobre la villa de Baena, haciendo referencia a una observación de Rodrigo Amador de los Ríos ${ }^{3}$ sobre la falta de documentación arqueológica de los primeros momentos de Al-Andalus dentro de la localidad, propone una posible ubicación de la primitiva Bayyāna diferente a la actual; Valverde y Perales basa esta teoría además en la toponimia de un paraje, el cortijo de la Peña de Omar y el cerro de la Antigua. Opina que en dicho cerro, a unos cuatro kilómetros del asiento actual de la población, estaría ubicada la primitiva Bayyāna y que el cercano cortijo de la Peña de Omar puede relacionarse con el pacto y posterior traición llevada a cabo por ‘Umar ïbn Hafșūn a la población de Bayyāna.

Suceso que comentaré más adelante y que para el mencionado historiador local resalta la importancia de Baena como plaza fuerte, siendo capaz de contener el embiste del ejército de İbn Hafșūn, que, viéndose impotente para rendirla, pacta con ella, para posteriormente traicionar a sus pobladores, condenándoles a la esclavitud y a la muerte.

La Enciclopedia del Islam sitúa a Baena "... dentro del distrito de Cabra y que junto con el de Azahara, Édia, Lucena y Córdoba formaban el iqlim d'al-Kambaniya o de la Campiña... gran prosperidad en época omeya. Posee una sólida fortaleza situada sobre la vertiente..., una mezquita catedral construida bajo las ordenes de Abd al-Rahman II, los bazares y los baños..." 4 .
No se ha llegado a realizar ninguna excavación arqueológica en el casco urbano baenense, salvo la infructuosa búsqueda de la Mezquita Aljama bajo la Iglesia Parroquial de Santa María la Mayor; realizada por Francisco Godoy $^{3}$. De igual resultado fue el intento para esclarecer la cimentación de la muralla medieval del barrio de la Almedina ${ }^{6}$.

Morena López ${ }^{7}$ realizó prospecciones en el término municipal y de dicho estudio se concluye que en los siguientes lugares se encuentran vestigios materiales de presencia islámica: cortijo de Adalid, cortijo de Alcoba Alta, cortijo de Alcoba Baja,Arroyuelos I, Buenavista I, cortijo de la Cabaña, la Casería, cortijo de Castillejo I, Cobatillas, los Coros, el Cuadrado, el Cuadradillo II, cortijo de la Delicia, el Despeñadero, cortijo de la Estrella, Fontanares, la Gamonosa III, Isla de Amores, cortijo de Mala Entrada, cortijo de Melenas, Peñón de la Miel, cortijo del Palomarejo I, cerro de la Pava, cortijo de Peña Omar, PérezEstrella Alto, Pérez- Es trella Bajo, cerro del Pero, Arroyo del Pilar, Casa de la Pradera, la Rabua, cerro de Santa Catalina o de la Antigua, cerro del Tejadillo, cortijo del Tejadillo Alto, cortijo de la Torre del Moro, cortijo de Vado Fresno, cortijo de Vado Mojón, loma de las Varillas, cerro de la Viña y el Zahurdón.

También mediante prospecciones arqueológicas en la mitad norte del término municipal Bernier Luque, Serrano Carrillo y Morena López ${ }^{8}$ señalan, entre la riqueza arqueológica

2 VALVERDEY PERALES, Francisco: (1903) Historia de la villa de Baena. Toledo.

3 AMADOR DE LOS RÍOS Y VILLALTA, Rodrigo: (I3, Marzo, 1897) "Baena en los días de la dominación musulmana", El Defensor de Baena. Baena. Creo interesante reproducir dicho artículo, ya que al haber sido publicado en un periódico local, y no en una revista científica o de mayor divulgación, es muy difícil su localización. El ejemplar con el que he trabajado pertenece a la biblioteca privada de D. Pablo Ramírez Jerez, descendiente de D. Rodrigo Amador de los Ríos, a quien agradezco las facilidades prestadas para consultar dicho material y biblioteca, así como el permitir su reproducción, tal y como se ha hecho en el Apéndice I.

4 HUICI MIRANDA, Antonio: "Bayyana”, Enciclopédie de l'Islam 2. Nouvelle Edition I A-B. P. I I 84.

5 GODOY DELGADO, Francisco: (1991) "Intervención arqueológica de urgencia en la Iglesia de Santa María la Mayor en Baena", Anuario Arqueológico de Andalucía. Actividades de urgencia, 1989. Sevilla. Pp. 127-I33.

6 Excavación realizada por José Escudero Aranda; ESCUDERO ARANDA, José: (1987) "Excavación de urgencia en la muralla de la Almedina de Baena (Córdoba) en 1985", Anuario Arqueológico de Andalucía. Actividades de urgencia, 1985. Sevilla. Pp. I2I-I22.

7 MORENA LÓPEZ, José Antonio: (1989) El santuario ibérico de Torreparedones. Castro del Río-Baena. Córdoba. Estudios cordobeses. Publicaciones de la Excelentísima Diputación Provincial. Córdoba; MORENA LÓPEZ, José Antonio: (1990) "Prospección arqueológica superficial de urgencia en los terrenos afectados por el trazado de la variante de Baena (Córdoba)", Anuario Arqueológico de Andalucía. Actividades de urgencia, 1990. Sevilla, 1992. Pp. 78-82.

8 BERNIER, Juan; SERRANO CARRILLO, Juan; MORENA LÓPEZ, José Antonio: (1984) Arqueología inédita de Córdoba y Jaén. Colección de Estudios Cordobeses, 35. Diputación Provincial de Córdoba. Córdoba. 
de la zona, varios asentamientos con material islámico, en ocasiones unido a material de periodos anteriores; romano, ibérico e incluso prehistórico. Entre estos señalar los asentamientos de continuidad temporal romano- medieval como el Cortijo del fardón, el Cortijo del Rebondillo, o el Villar, mientras que en los yacimientos del Cueto, el Carmen, Mirabuenos o Villamarín, se encuentran, junto con la cerámica común romana, las tégulas, la sigillata y las medievales vidriadas, cerámicas ibéricas y del Bronce.

En cambio, los asentamientos conocidos como Amarguitos y Arroyuelos II son puramente árabes, encuadrando los restos cerámicos en las tipologías califales y cabe señalar que en el primero de ambos se sabe de la existencia de un hallazgo de monedas árabes de plata, de época califal, que ha sido estudiado por Cardito, Martínez y Sevilla 9; quienes en dicho estudio opinan que el conjunto total de piezas sería mayor que el conservado y que se encontraría depositado dentro de un recipiente, a juzgar por el tamaño de los fragmentos. Esta segunda afirmación puede ser criticable si tenemos en cuenta los últimos estudios realizados sobre fragmentación de moneda califal ${ }^{10}$ debido a la amplia variedad de tamaños que surgen de esta práctica, realizada a propósito, con fines comerciales.

Este hallazgo monetario, formado por 27 monedas enteras y 97 fragmentos, pertenece al periodo califal, como hemos señalado anteriormente, con unas fechas de cierre del con- junto de $323 \mathrm{H}$ a $401 \mathrm{H} . / 934$ a 1010 d.C. Cabe señalar la presencia de seis fragmentos de moneda fatimí.

De similar fecha de cierre es el conjunto monetario estudiado por Navarro Oltra " depositado en el Museo de Alicante el 21 de Junio de 1972, procedente de la colección de Don Antonio Quiles. Una nota informa sobre su lugar, fecha y modo de aparición, así como de su composición. El hallazgo tuvo lugar en el término municipal de Baena, motivo por el cual señalamos aquí su existencia, concretamente en La Valeriana, en el año I882, en una olla, debajo de una encina. Está compuesto por cincuenta dirhames califales, aunque posiblemente, en el momento del hallazgo, este número fuese mayor y su fecha de cierre, el año 400H./ 1009 d. C., en piezas de Sulayman al-Mustacīn, coincide con momentos de gran tensión a fines del califato cordobés.

Pero también encontramos conjuntos numismáticos de momentos anteriores: una mera referencia a un hallazgo de dirhames del Emirato Dependiente ${ }^{12}$, aparecido en el año 1924, comprado por la Comisión Provincial de Monumentos Histórico-Artísticos de Córdoba y depositado en el Museo Arqueológico Provincial de Córdoba ${ }^{13}$, que se compone de 35 I piezas de plata, entre dirhames enteros y fragmentos. Son 25 las cecas presentes, y las fechas de 79 a 136H./698-753 d. C. Su fecha de cierre coincide con el momento en el que 'Abd al-Raḥmān I se establece, tras diversos enfrentamientos, en Al-Andalus, como 'āmir ${ }^{14}$.

9 CARDITO, Luz; MARTíNEZ SALVADOR, Carmen; SEVILLA, Covadonga: (1993) "Hallazgo de moneda islámica en Baena, Córdoba", III Jarique de Numismática Hispano-Árabe. Madrid. Pp. 287-295.

I0 RUÍZ QUINTANAR, Lourdes: La fragmentación de moneda en época omeya: el hallazgo califal de Haza del Carmen. Memoria de Licenciatura dirigida por el Dr. Alberto Canto García. Facultad de Geografía e Historia. Departamento de Prehistoria y Arqueología. Universidad Autónoma de Madrid. Madrid. I tomo.

I I NAVARRO OLTRA, Caries Vicent: (I99|) “Troballa de dirhems califals a Baena (Córdova), anys 330-400 H.”, Gaceta Numismática, I03. Pp. 7-I5

I2 MARTíN ESCUDERO, Fátima (200I): "El hallazgo omeya de Baena: un tesoro olvidado", Actas IV Jarique de Numismática Andalusí, Jaén. Pp. 8I-94; MARTíN ESCUDERO, Fátima: (200 I ) "Tesoro de Baena”, El esplendor de los Omeyas cordobeses. La civilización musulmana de Europa Occidental. Catálogo de piezas. P. II I.

13 Números de Inventario 3646 a 3735 y 3748 a 3760 del Museo Arqueológico Provincial de Córdoba.

I4 MARTÍN ESCUDERO, Fátima (200 I) Pp. 8 I-94. Op. cit. nota I2; MARTíN ESCUDERO, Fátima: El tesoro de moneda omeya de Baena (Córdoba): una hipótesis sobre circulación monetaria. Memoria de Licenciatura dirigida por el Dr. Alberto Canto García. Facultad de Geografía e Historia. Departamento de Prehistoria y Arqueología. Universidad Autónoma de Madrid. Madrid. I tomo. Leída el 29 de junio de 2001 . 
En el Emirato Independiente, y con una cronología del 162 al 272H./778 al 885 d. C., se encuadra un tesorillo de cincuenta dirhames estudiado por Almudena Ariza Armada ${ }^{15}$, que apareció cercano al Cortijo de Izcar, en 1985, Mientras se realizaban labores agrícolas. Y por último señalar el conocimiento que tenemos, a través de particulares, de la existencia de hallazgos ocasionales de moneda árabe dentro del término de Baena.

Otro testimonio artístico hallado en Baena, desgraciadamente sin contexto arqueológico, es un relieve decorativo mural. Fue encontrado en el Convento de Madre de Dios y actualmente se encuentra depositado en el Museo Arqueológico de Sevilla ${ }^{16}$, Se trata del fragmento superior de un panel dispuesto en un muro o jamba de puerta, y a pesar de haberse hallado en Baena, se opina que su posible ubicación original fuese el Salón Rico o de 'Abd al-Rahmān III, en Madinat al-Zahrā' por su estilo y técnica decorativa ${ }^{17}$, y por tanto fechado en la segunda mitad del siglo $X$, en pleno Califato.

Estas son las primeras noticias directas que poseemos sobre la Baena islámica, pues bien parece respecto a las fuentes escritas lo que D. Rodrigo Amador de los Ríos afirma refiriéndose a dicha villa, en el prólogo que realiza a la Historia de la villa de Baena de Valverde y Perales 18: "...Perdido se muestra todo rastro en los de la dominación musulmana, cual si por allí jamás hubieran aparecido sectarios del Islam..."

Pero comencemos por el principio; Baena pertenecía a la cora de Qabra, que limitaba al este con la cora de Ŷayyan (Jaén) y la de Elvi ra; al sur con la cora de Rayyo (Archidona); al oeste, con frontera en el río Genil, con la cora de Istichcha (Écija); y al norte estaba el iqlïm de Uliya (en el que se encuadran Fernán Nuñez y Montemayor).

Este territorio, relativamente pequeño, coincidía en sus límites con la diócesis visigoda de Cabra y surge como centro militar y administrativo al sur de Córdoba. Además era lugar de paso, por los caminos que se entrecruzaban en dicho territorio: de Córdoba a Elvira, pasando por Baena, de Córdoba a Málaga, de Baena a Poley, atravesando Cabra. Este se trata de una antigua calzada romana, conocida en el siglo XII como camino de Metedores o de la Plata. Baena estuvo dentro del recorrido de las tropas beréberes de Ṭāriq durante la conquista, de Écija a Toledo, a través de Mentesa.

La cora de Qabra, con una alta densidad de población, comprendía varias ciudades o medinas: Qabra (Cabra), ciudad que cede su nombre a la cora y que durante los primeros tiempos de Al-Andalus fue la capital; capitalidad que pasa a Bayyāna (Baena) a finales del siglo IX d. C.; al-Yussana (Lucena), con una mayoritaria población judía; el castillo de Bulayy posteriormente conocido como Poley y actualmente coincidente con Aguilar de la Frontera; el castillo de Monturk (Monturque); Montilla; Lukk (Luque), que pertenecía al distrito de Baena; y una serie de poblaciones no identificadas como Yarmala, Yarula, Istijana, Chalina y Wāsit. De esta última dice Yaqut en su Diccionario de los países (Mu'chan al-Buldan) que es un pueblecito dependiente de Cabra. Arjona Castro ${ }^{19}$ se plantea si dicho nombre corresponde a una

\footnotetext{
I5 ARIZA ARMADA, Almudena: (Junio 1993) "Un tesorillo de dirhemes de Baena (Córdoba)", Gaceta Numismática I09, II. Asociación Numismática Española. Barcelona. Pp. 33-39.

16 Número de inventario R. E. P. 4.421 del Museo Arqueológico de Sevilla.

I' MARTÍN GÓMEZ, Carmen: (200I) "Relieve decorativo mural", El esplendor de los Omeyas cordobeses. La civilización musulmana de Europa Occidental. Catálogo de piezas. P. 165.

I 8 VALVERDE Y PERALES, Francisco: (1903). Op. cit. nota 2. Prólogo de Rodrigo Amador de los Ríos. Pp. IX-XXV, concretamente p. $X V I I I$.

19 ARJONA CASTRO, Antonio: (1978) "La cora de Cabra", Actas I Congreso Historia de Andalucía. Andalucía Medieval. Tomo I. Publicaciones del Monte de Piedad y Caja de Ahorros de Córdoba. Córdoba. Pp. 61-75.
} 
tribu procedente del Wāsit oriental asentada en esta zona, basándose en la nisba de un personaje biografiado por Ibn Baskwal, dicha nisba sería Wāsit Qabra.

Además de estas poblaciones Vallvé ${ }^{20}$ señala la existencia de más de 630 alquerías, 300 torres $^{21}$ y unos 70 castillos,

Según las fuentes escritas más arriba comentadas, destaca la zona por su riqueza agrícola y ganadera, sus olivos, viñas, higueras, cereales, árboles frutales y productos hortícolas, regados por los ríos Marbella, Cabra o Genil, junto a los que surgían numerosos molinos.

Arjona Castro ${ }^{22}$ propone que el nombre de Bayyāna deriva de un personaje llamado Baius, según deduce del sufijo personal -ana, teniendo su origen en una antigua villa romana que pervivió como cabeza de latifundio hasta época visigoda y allí será donde se asiente la nueva población islámica, resurgiendo como centro administrativo, político y militar. La formación del nombre de las villae reocupadas con antropónimos latinos más el sufijo - ana es una idea recogida también por Acién Almansa ${ }^{23}$. Además de esta sugerente hipótesis, existe otra en la que Bayyāna, la Baena árabe, sería derivación de Baniana, población ya señalada por Ptolomeo.

Los árabes, que acompañaban a Mūsa' ibn Nușayr en su campaña hispana, los conquistadores, al igual que casi toda la población árabe que posteriormente llegue a la Península Ibérica, entre los que cabe destacar a los miembros del yund, se asentarán en zonas con un clima benigno, en fincas de tierra fructífera usurpadas a los indígenas o en centros de población mixta, junto a población indígena en centros agrícolas originados a partir de antiguas villae o alrededor de o en núcleos urbanos. Generalmente en zonas situadas cercanas al valle del Guadalquivir o afluentes y que políticamente están supeditadas al estado emiral ${ }^{24}$. Podríamos ver aquí un fiel reflejo del proceso seguido en Bayyāna, teoría ya apuntada por Valverde y Perales ${ }^{25}$ y avalada por la prospección realizada por Morena López ${ }^{26}$, en la que afirma que el asentamiento prospectado en el cerro de la Antigua sería una villa romana con continuidad medieval.

Respecto a la población árabe de Bayyāna sabemos, por la Yamharat al-Ansab de Ibn Hazm, que entre esta se encontraban los Banu 'Amarb, que tomaran su nisba de Muzayana, esposa de Udd. También se establecieron árabes Muḍaries, del Norte, descendientes de 'Adnan.

El grueso de la población árabe supuestamente llegaría a la zona en el año 135H./752 d. C., cuando Abü-l-Hattāar distribuye al ŷund sirio llegado a la Península en el 124H./74l d. C. para sofocar la rebelión beréber y que se había asentado en Córdoba. El ŷund del Jordán será ubicado en la cora de Rayyo, pero no permaneció en la capital de dicha cora, Archidona, sino que se diseminó por sus territorios y

20 VALLVÉ BERMEjO, Joaquín: (1986) La división territorial de la España musulmana. C.S.l.C. Departamento de Estudios Árabes. Madrid.

2I Entre dichas torres destacaremos la atalaya conocida como "la torre del Montecillo" o "torre Morana" (Lám. I), ubicada cerca de la carretera A-305, que une Baena y Albendín (pedanía de dicha localidad) y que creemos es, dentro del término municipal de Baena, la que mejor se conserva.

22 ARJONA CASTRO, Antonio: (1982) El reino de Córdoba durante la dominación musulmana. Córdoba.

23 ACIÉN ALMANSA, Manuel: (1999) "Poblamiento indígena en Al-Andalus e indicios del primer poblamiento andalusi", Al-Qantara, XX, I. C.S.I.C. Madrid. Pp. 47-63.

24 ACIÉN ALMANSA, Manuel: (1998) "La desarticulación de la sociedad visigoda", Hispania, Al-Andalus, Castilla. Jornadas históricas del Alto Guadalquivir. Salvatierra Cuenca, V. (ed.). Jaén. Pp. 45-67.

25 VALVERDE Y PERALES, Francisco: (1903). Op. cit. nota 2.

26 MORENA LÓPEZ, José Antonio: (1990) "Prospección arqueológica superficial de urgencia en los terrenos afectados por el trazado de la variante de Baena (Córdoba)", Anuario Arqueológico de Andalucía. Actividades de urgencia. Sevilla, 1992. Pp. 78-82. 
con toda seguridad se expandieron por la cora de Qabra, antigua sede episcopal en época visigoda, para así realizar su recolección tributaria y actuar conjuntamente en el ámbito militar. Esta unión se mantendrá durante el califato, así se nos muestra cuando juntos acudan a una audiencia a los notables ofrecida por el califa al-Hakam "...compareciesen ante el Príncipe de los Creyentes...el yund del Jordán, que son la gente de la cora de Rayyu, a la que se unió la gente de la cora de Cabra, Baena y Poley." 27.

Plantean Salvatierra Cuenca et alii ${ }^{28}$ para el caso de Jaén la escasa presencia de otros grupos árabes o beréberes debido al asentamiento en la zona de miembros del ŷund sirio, teniendo en cuenta los enfrentamientos entre ambos grupos. Similar pauta de asentamiento podía ser aplicada en el estudio de la composición de la población de Bayyāna, pero no olvidemos que será una mera hipótesis.

Bayyána ,junto con la cora de Qabra, estará unida al devenir de la cora de Rayyo, y de ésta interesa destacar tres acontecimientos; el primero será el pacto realizado por Yahya ibn Hurayț al-ŶYudāmī y $\hat{Y} u ̄ s u f$ al-Fihrĩ, ofreciéndole este segundo a Yahya el gobierno de la cora de Rayyo a cambio de su apoyo en el ascenso al poder como wālī. Pero Ŷūsuf lo destituyó y Yahya se unirá a Abū-l-Hațtāar e iniciará una rebelión, prontamente sofocada, contra el gobernador cordobés.

El segundo está relacionado con la llegada a la Península de 'Abd al-Rahmān I y el apoyo que los territorios donde está asentado el ŷund sirio le dispensan. Ŷūsuf al-Fihri le ofreció como pacto la mano de su hija y el gobierno de las coral donde se asentaban el ŷund del Jordán (en la cora de Rayyo y Málaga) y el de Dimišq (asentado en la cora de llbira), lo que solucionaría su falta de recursos.

El último acontecimiento a resaltar es que en dicho territorio se proclama durante la fiesta de la Ruptura del Ayuno a 'Abd al-Rahmān ibn Mucāwiya como 'āmir.

Ya durante el Emirato Independiente ${ }^{c} A b d$ al-Raḥmān II impone un modelo político abbasí, integrador de toda la población, sin ningún tipo de preponderancia árabe, mediante la utilización del Islam como religión estatal, desarrollando la administración e impulsando la urbanización con la construcción de nuevas ciudades o los elementos que las configuren: mezquitas y murallas. Por este motivo será construida la mezquita de Baena y probablemente también sus murallas, con torreones cuadrados, aunque sobre la construcción de estas nada mencionen las fuentes.

La ubicación del edificio religioso se supone bajo la Iglesia de Santa María la Mayor, que ocupa una posición principal, en la Almedina, cerca del castillo y cuya única torre es de construcción árabe, a la que se le ha añadido un cuerpo de campanas. Rodrigo Amador de los Ríos 29 supuso, ante la falta de restos arquitectónicos andalusíes, que: "..en Baena hubo de ocurrir con este templo lo propio que aconteció con la catedral de Sevilla: que la mezquita, más ó menos reformada, subsistió probablemente hasta la segunda mitad del siglo $\mathrm{XV}$, en que fué demolida, para sacar entonces de cimientos, con orientación contraria, la Parroquia hoy existente". En 1989, con motivo de unas obras de restauración de dicho templo, se realizó una intervención arqueológica, dirigida por E Godoy Delgado ${ }^{30}$, quien supu-

27 Texto del Muqtabis de Ibn Hayyan, recogido por Arjona Castro; ARJONA CASTRO, Antonio: (1982) Anales de Córdoba musulmana (7/ - 1008). Publicaciones del Monte de Piedad y Caja de Ahorros de Córdoba. Córdoba.

28 SALVATIERRA CUENCA, Vicente; SERRANO PEÑA, José Luis; PÉREZ MARTíNEZ, Ma Carmen: (1998) "La formación de la ciudad en al-Andalus. Elementos para una nueva propuesta", Genése de la ville islamique en al-Andalus et au Maghreb occidental. Cressier, P. y García-Arenal, M. (eds.). Casa de Velázquez-CSIC. Madrid. Pp. 185-206.

29 AMADOR DE LOS RÍOS Y VILLALTA, Rodrigo: (30 de diciembre, 1902) "Recuerdos de Baena (Córdoba). La parroquia de Santa María la Mayor", La llustración Española y Americana. Pp. 504-5। 4.

30 GODOY DELGADO, Francisco: (199I). Op. cit. nota 5. 
so, siguiendo los testimonios de Valverde y Perales ${ }^{31}$ respecto a la anterior disposición de la iglesia en dirección Norte-Sur, transversal a la actual, que el templo cristiano aprovecharía en parte la planta de la mezquita, y por tanto esta tendn'a "el modelo andalusí de la torre al Norte, el oratorio al Sur y, entre ambos, el patio de abluciones". Pero los resultados de tal excavación fueron nulos respecto al periodo islámico, quizás bastante arrasado por las criptas construidas bajo las capillas actuales. Lo que sí nos confirma Godoy Delgado es la cronología emiral, concretamente de época de 'Abd al-Rahmmān II de la obra del alminar, actual torre de la iglesia, por su tipo de aparejo (alternancia de una soga y uno o dos tizones), la altura de sus sillares y la poca longitud de las sogas, lo que la hace asimilable al alminar de la iglesia de Santiago, en Córdoba.

Bayyána aparece en las fuentes en relación con la rebelión muladí de CUmar ỉbn Hafșūn, conocida como la primera fitna, que surge en la serranía de Ronda y realiza incursiones por el territorio afín al estado emiral, solicitando el apoyo de los gobernadores estatales, tal es el caso de Jaén o llbirra. Pero la oposición también surge en los medios rurales, así ocurrirá en Bayyāna, que logrará conquistar en el año 276H./6 de mayo 899 a 25 de abril 890 d. C. traicionando a la población, pues "lo atacó y su gente le resistió y lo combatió", tras este intento infructuoso de conquistar la fortaleza, Ibn Hafșūn pacta y cuando se le abren las puertas el rebelde romperá la alianza y atacará el hișn: "cuando descendieron a él, los aprisionó y mató a un grupo de ellos, se apoderó de sus bienes, azotó a su prole, y se dirigió con todo su botín y lo saqueó" 32 y será aquí donde en el año $277 \mathrm{H}$./ 890-89 | d. C. lleve presos a IbráhTm ibn Jamir y otros miembros del ejército emiral, apresa dos en Priego de Córdoba, zona afín al rebelde. Este mismo año el emir c $A b d$ Allāh vence a 'Umar íbn Hafșūn en Bulayy (Aguilar de la Frontera) y establece un cuerpo de caballería en la alcazaba de Baena, con fines estratégicos por el control del valle del río Guadajoz, vía natural de penetración desde Priego de Córdoba a Córdoba.

Valverde y Perales ${ }^{33}$ sitúa el cambio de asentamiento de Bayyána del cerro de la Antigua a su ubicación actual tras la traición de đUmar ībn Hafșun y antes de la instalación en la alcazaba de Bayyāna del cuerpo de caballería del ejército emiral. Sin embargo este cambio de ubicación tuvo que realizarse tiempo antes, pues, como ya he comentado, la construcción de la mezquita de Bayyāna, ya en su asentamiento actual, tuvo lugar durante el gobierno de 'Abd al-Raḥmān II. Otra posibilidad sería la existencia de los dos núcleos poblacionales en un momento coetáneo, pero que tras el ataque de íbn Hafșūn la población asentada en el Cerro de la Antigua lo abandonase trasladándose a la ya emergente madina de Bayyāna. Esta posibilidad se nos muestra remota, ya que por los restos conservados en el denominado Cerro de la Antigua no hay muestra de grandes construcciones como murallas que pudieran parar el embiste hafsuní, además de que en las fuentes quedaría reflejada su lucha o pacto con el otro núcleo, por lo que planteamos la hipótesis de que el centro que realmente rechazase el ataque del rebelde íbn Hafșūn fuese Bayyāna, en su actual ubicación.

Aplicable a la hipótesis expuesta, Gutiérrez Lloret 34 recoge la idea del abandono de la ciudad antigua "coincidiendo con el desarrollo de nuevos núcleos de poblamiento en sus inmediaciones. La relación mecánica entre ambos fenó-

3I VALVERDEY PERALES, Francisco: (1903) Op. cit. nota 2.

32 Texto de Ibn Hayyan, del Muqtabis III, recogido por Acién Almansa; ACIÉN ALMANSA, Manuel: (1997) Entre el feudalismo y el Islam. Umar Ibn Hafsun en los historiadores, en las fuentes y en la historia. Universidad de Jaén. Jaén.

33 VALVERDE Y PERALES, Francisco: (1903) Op. cit. nota 2.

34 GUTIÉRREZ LLORET, Sonia: (1998) "Ciudades y conquista. El fin de las civitates visigodas y la génesis de las mudun islámicas del sureste de al-Andalus", Genése de la ville islamique en al-Andalus et au Maghreb occidental. Cressier, P.y García-Arenal, M. (eds.). Casa de Velázquez-C.S.I.C. Madrid. Pp. I37-I57. 
menos, que supone como premisa el desplazamiento de población, ha llevado a establecer binomios de continuidad entre la ciudad destruida de origen romano y su supuesta reconstrucción islámica a unos cuantos kilómetros".

Tras la derrota de cUmar íbn Hafsūn y la llegada del cuerpo de caballería a Bayyāna, la capitalidad de la cora pasa de Cabra a Baena, hecho reflejado en la Crónica anónima de ${ }^{`} A b d$ al-Raḥmān III, que ya en el año 318H./930 d.C. es nombrado gobernador de Baena y sus contornos Abu-I-Sa'ra ibn 'Abd al-Rahmmān, dividiéndose la cora en dos, siendo antes Baena gobernada con jurisdicción autónoma por Ahmad ibn Sarahil.

Poco sabemos de Baena durante el periodo califal, salvo su próspero crecimiento y el despunte de alguno de sus ciudadanos, como Qāsim ibn Asbag (247-340H/ 86I-95I d. C.), célebre polígrafo de textos coránicos y de Las excelencias de los Omeyas, historia no objetiva de los emires cordobeses. Era mawlā de los Omeyas, entre sus antepasados se encontraba un liberto del califa omeya al-Walìd I. Otros ciudadanos excepcionales fueron 'Alī ibn Moads "gran hablista, poeta y genealogista" y Yaix ibn Said, escritor distinguido por al-Hakam II.

Tras la caída del califato Baena es saqueada por beréberes, que interrumpen su próspero crecimiento. Y el || de Julió del año ||65 d. C., en el nacimiento del río Marbella, junto al abrevadero del río Luque batallarán almo- hades y almorávides. Del paso de ambos por la localidad ha quedado constancia en la torre coracha llamada Torre del Sol (Lám. 2) y las entradas en recodo de la muralla de la Almedina; de tipología almorávide es la conocida como Arco de la Consolación (Lám. 3) y almohade el Arco Oscuro (Lám. 4).
No hemos hallado constancia de la fecha de construcción de la alcazaba árabe de Baena; sin embargo sí tenemos algunos datos, aunque escasos de su posterior disposición, tales como: "El Castillo ó fortaleza bajo cuya custodia y defensa estuvo siempre la villa de Baena, forma un gran cuadrado guarnecido de robustos baluartes y espesas torres, sin que apenas se descubran hoy en él rastros de su origen árabe, cuyas huellas han borrado las obras importantes que, en épocas posteriores á la Reconquista, ampliaron y mejoraron sus defensas... Se arruinó la antigua capilla que, á juzgar por dos columnas con capiteles árabes que quedaban en ella en los pasados años, debió ser la mezquita de la fortaleza durante la dominación musulmana." 35

En él se halló una yesería de traza granadina con tarjetones superior e inferior con leyendas en nesjí ${ }^{36}$, que dicen:

Tarjetón superior:

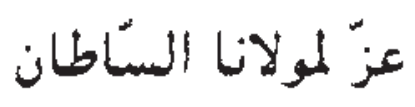

Ensalzado sea nuestro señor el Sultán!

Tarjetón inferior:

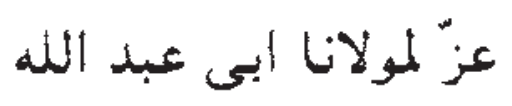

Ensalzado sea nuestro señor Abú-Abd-il-Láh!

Algunos de estos tableros fueron cedidos por el Marqués de Corvera, propietario del Castillo de Baena a principios del siglo $X X$, al Museo Arqueológico Nacional. Rodrigo Amador de los Ríos calibró la posibilidad de que estos motivos decorativos hubiesen sido rea-

35 VALVERDEY PERALES, Francisco: (1903) Op. cit. nota 2. Concretamente p. I 5 I.

36 Esta inscripción fue documentada ya en 1879 por Rodrigo Amador de los Ríos, publicándola posteriormente en AMADOR DE LOS RÍOS, Rodrigo: ( 1883 ) Memoria acerca de algunas inscripciones arábigas de España y Portugal. P. I40.; AMADOR DE LOS RÍOS, Rodrigo: (1907) "Notas acerca de la batalla de Lucena y de la prisión de Boabdil en I483", Revista de Archivos, Bibliotecas y Museos, XVI. Pp. 36-66 y particularmente pp. 4I-44. 
lizados por la supuesta presencia de Muhammad XI en dicho castillo tras la batalla de Lucena ${ }^{37}$.

Pero será en el año 1240 d. C. cuando el monarca castellano Fernando III, el Santo, conquiste Córdoba y en un corto periodo de tiempo gran número de pueblos de la campiña, entre los que se encontraba Baena, que llegó a manos cristianas en el año $|24|$ d. C. Probablemente se entregasen sin resistencia, por el breve periodo de "reconquista".

Será a partir de ahora cuando Bayyāna se convierta en la Baena cristiana, y no volverá bajo dominio islámico, aunque, por su posición fronteriza con el reino de Granada, no se deslindará de sus aconteceres ${ }^{38}$.

37 AMADOR DE LOS RÍOS, Rodrigo: (1907). Op. cit. nota 36

38 Así, en efecto sabemos que al ser territorio fronterizo fue objeto de diversas escaramuzas, como la efectuada por Muhammad I I, rey de Granada “...y reuniendo en Granada poderoso ejército el Rey Mohamad I I, el año de I300, partió hacia la frontera cristiana, y poniendo sitio á Alcaudete, que pertenecía á la Orden de Calatrava, logró rendirla tras porfiados asaltos, apoderándose de ella. De allí marchó sobre Baena, de cuyo castillo era Alcaide Alfonso Pérez de Saavedra, y acometiéndola con brío en repetidos ataques, puso en grave aprieto á sus valientes defensores que, ayudados por los vecinos, lograron rechazar á los envalentonados moros... Desesperanzados los moros de rendir Villa tan fuerte y tan heroicamente defendida, levantaron el cerco, no sin haber incendiado un arrabal..." (vid. VALVERDE Y PERALES, Francisco: (1903) Op. cit. nota 2. Pp. 164-65, y otros enfrentamientos entre ambos reinos en la zona de Baena en pp. 8I-82). Incluso aún existe la tradición de creer que tras la batalla de Lucena Muhammad Xl, último rey de Granada, conocido popularmente como Boabdil, permaneció preso en el castillo de Baena, que pertenecía a los señores de la Casa de Córdoba, vid. AMADOR DE LOS RÍOS, Rodrigo: (1907) Op. cit. nota 36, interesante artículo en el que analizan diferentes textos para intentar dirimir el asunto de si la prisión de Muhammod XI tuvo lugar en Baena o en Lucena y señala cómo Hernando del Pulgar, Nebrija, Garibay y Aureliano Femández-Guerra apoyan la primera opción. F.Valverde y Perales presenta incluso un documento fechado en 19 de diciembre de 1786 que dice así "...el Castillo está Cercado de Fuertes y bien formadas Murallas y Baluartes, con sus Plazas de Armas, y en una de dichas torres, conocida por de las Arqueras, que haze fachada al Poniente y Sur y tiene cinco Esquinas, estuvo preso el Rey Chico de Granada, en un cóncavo de la pared que mira al Lebante", torre perteneciente al, en la actualidad, ruinoso castillo de Baena. VALVERDE Y PERALES, Francisco: (1903), pp. 152. Op. cit. nota 2. 


\section{APÉNDICE I *}

\section{Baena en los días de la dominación musulmana}

Difícil tarea ha sido siempre, -cuando en los incesantes vaivenes, $y$ en las reiteradas vicisitudes de la vida se ha desvanecido toda memoria, y se ha confundido al par todo recuerdo- el rastrear á través de los tiempos, y, lo que es más grave aún, á través de las sombras de lo desconocido, la historia de una población cualquiera, si ni existen ni se conservan restos indicadores que contribuyan, por algún camino, á hacer practicable por lo menos el que se pretende seguir ó establecer, en medio de errores, apasionamientos y dudas, los cuales más imposibilitan el tránsito, y más peligroso y ocasionado convierten el empeño.

Tal, y no otra cosa, ocurre en realidad con relación á la importante villa de Baena, en la provincia de Córdoba. Sus encomiadores y panegiristas, en alas del laudable deseo de exaltar el origen, y ponderar el prestigio de la villa en todas las edades, buscaron para ella exclarecido abolengo, y llevaron la antigüedad de la misma á épocas remotas, sin recelo de error, y con la seguridad del acierto.

Por desventura, nada ha venido á comprobar sus afirmaciones, dentro del perímetro actual de la villa, si bien en los contornos de ésta los testimonios abundan, acreditando con singularísima elocuencia que hubo población romana en los lugares próximos á Baena, y en los de su jurisdicción y término, circunstancias una y otra que, conocidos los sitios en que se han verificado los hallazgos, despojan de toda autoridad, á lo que parece, el supuesto de aquellos que no vacilan en concertar la población romana existente en las cercanías de la villa, y aun en la villa misma, según los escritores á quienes aludimos, con la Julia Regia y con la Baniana ó Biniana de Tolomeo.

El doctor Hübner, cuya competencia en estos estudios no es para puesta en tela de juicio, confiesa paladinamente que es dudoso el lugar donde tuvo su emplazamiento la población ', y no falta quien sospeche que la primitiva Julia Regia, cuyo nombre anterior al triunfo de César se desconoce, así como la Baniana de Tolomeo, estuvieron en sitio diferente del actual perímetro de Baena.

Si la población romana anterior y posterior á Julio César estuvo en los lugares próximos al Cortijo de las Vírgenes, donde fueron en 1833 halladas fortuitamente las urnas cinerarias de los Pompeyos, ó en cualquiera otro de aquellos en que han aparecido epígrafes, conveniente sería averiguar la causa que determinó el traslado de la población, y la época en que hubo éste de verificarse, por más de que la carencia de monumentos romanos y visigodos en el perímetro de la villa actual, parece acreditar el supuesto de que el traslado debió efectuarse después de la invasión mahometana, y acaso en el siglo III de la Hégira (IX de J. C.).

Ya antes de esta época, si la población romana tuvo proporcionada importancia, -cosa que pondrían, ó hubieran sin duda puesto de manifiesto, como en otras partes, las reliquias monumentales, ya arquitectónicas ya escultóricas, que habrían aparecido juntamente con las litológicas,- debió de haber perdido todo prestigio en la edad visigoda, antes y después de Leovigildo, cuando no queda rastro ni monumental ni epigráfico de ella, conjeturándose que hubo de sufrir grave devastación en las luchas promovidas por el famoso Ómar-ben-Hafssón, durante la guerra social de los días de Mohámmad I y Ab-ul-Láh, y que quizás entonces quedó destruida.

Refiere con efecto Aben-Adharí de Marruecos que habiendo en 276 H. (889 á 890 J. C.) solicitado y obtenido Ómar el amán de parte del Califa Abd-ul-Láh, trascurrido algún tiempo, dentro del mismo año, "rompió el pacto...y se dirigió á Bayena (Baena), y luchó con sus habitantes." "Después, les concedió alianza; pero cuando éstos salieron á él, les hizo traición, y les dió muerte, y se apoderó de sus bienes y cautivó sus familias" 2 .

Parece pues, de semejante noticia deducirse sin violencia, que Baena, al conservar á través de los tiempos el nombre con que Aben-Adhari la designa, pudo ser acaso por esta circunstancia la Baniana de Tolomeo, por que sabido es que los musulmanes perpetuaron, aunque transformándolos, los

\footnotetext{
* Reproducción del artículo periodístico de Rodrigo Amador de los Ríos "Baena en los días de la dominación musulmana", publicado en El Defensor de Baena, el día 13 de marzo de 1897.

I "Corpus inscriptionum Hispaniae latinae" pág. 213.

2 "Bayan-ul-Mogrib" t. I. pág. 126; 236 de la trad. esp. de Fernández y González.
} 
nombres de las poblaciones que encontraron en España, y el de Baena ó Bayena, guarda cierto paralelismo con el de Baniana; que, como fronteriza con el clima ó distrito de Rayya ó Málaga en el de la Campiña, no había seguramente perdido del todo su antigua importancia, cuando detenía en la fecha indicada las tropas de Ómar, y obligaba á éste á pactar con sus habitantes, confesándose impotente así para apoderarse de ella por la fuerza; que permeneció siempre fiel á la autoridad de los Califas, y, por último, que hubo de experimentar grave quebranto en sus pobladores, y probablemente en sus defensas, á consecuencia de la conducta aleve que observó con ella el célebre caudillo muladí, faltando á lo pactado, haciendo dar muerte á gran número de baenenses, saqueando la villa, y cautivando no pocos de sus habitantes.

Teatro con frecuencia aquella parte de la actual provincia de Córdoba, de la lucha sostenida contra la autoridad califal por Aben-Hafssón, hubo de sufrir sin duda grandes trastornos que debieron alcanzar á Baena en los años sucesivos, no haciendo sin embargo mención de esta villa en las historias hasta el de 298 de la H. (9l0 á 9II de J. C.) en la cual cuenta el ya citado Aben-Adhari, que después de haber combatido el ejército del Califa el famoso castillo de Bobastro, -confundido por Conde y por Lafuente con Barbastro,- y otros varios de la cora ó comarca de Rayya; después de haber asolado los sembrados, y de haber destruido los frutos de la de Elbira ó Granada, el jefe de la caballería califal Isaben-Ahmed-ben-Abi-Abdá, "permaneció... con unos pocos caballos en Medina Bayena," y habiendo algareado "Ómar-ben-Hafssón y Said-ben-Mastena por la llanura de Cabra, y las alquerías de Córdoba, haciendo presa de ganados, salió Isa-ben-Ahmed (de Baena) á perseguirlos; y como encontrase á los dos junto al rio Alia, se empeñó entre ellos batalla reñida, siendo puestos en fuga Ómar-ben-Hafssón y Aben-Mastena, quedando muertos bastantes de los suyos, siendo libertados muchos cautivos, y enviando (á Córdoba) Isa-ben-Ahmed considerable número de sus cabezas" (las de los vencidos) ${ }^{3}$.

De reparar es que, procediendo estas noticias, reproducidas por Aben-Adhari, de la Crónica de Aúb, escritor del siglo X, se dé en la del año 298 título y categoría de Medina (urbs) á Baena, y que después del desastre de 276, fuese considerada, entre las restantes poblaciones de la campiña, como capaz de servir de base para ulteriores operaciones militares, lo cual acredita que era ciudad fortificada y distinguida por su importancia.

Todo hace semblante de acreditar que durante la centuria IV de la H. (X de J. C.) Baena hubo de conservar estas condiciones, ignorándose cuál pudo ser su suerte desde la disolución del Califato en 1036 hasta el siglo XII, en que escribe Xarif-AlEdrisí; pero es de presumir que en esta ocasión debió de haber como población llegado á gran decadencia, cuando el referido geógrafo, que compara á una ciudad la plaza de Cabra, no apellida ya á Baena Medina, según lo hace Aben-Adharí, sino que la describe diciendo: "De Alcaudete á la plaza fuerte de Baena (Bayena), hay una jornada corta." "Baena es una plaza fuerte de importancia, situada en la cima de una eminencia, rodeada de olivares, y que tiene sembrados de trigo y de cebada" 4

Por esta descripción, échase de ver que la plaza á que alude el Edrisí, quedaba reducida á los antiguos límites de la villa, la cual "estuvo sobre un cerro rodeado de dos órdenes de murallas, de los cuales el primero contenía la parte principal de la población, llamada la al-Medina..., y el segundo llegaba hasta los márgenes del rio Marbella," haciendo mucho tiempo que tales recintos están destruidos en parte é interrumpidos de manera, "que por algunos garages ni aun se conoce que hayan existido" 5 .

Al amparo de las fortificaciones señaladas por ambos recintos, la villa se ha extendido hácia el llano por la ladera del cerro, disposición en que hubieron sin duda de encontrarla los guerreros de San Fernando que en 1240 se apoderaron de ella, no siendo de maravillar por consiguiente, si el paralelismo de Bayena y Baniana puede autorizar el supuesto de que fueron una misma población, que en el perímetro actual de la villa no aparezca monumento alguno de la época romana ni de la visigoda, por más que extrañe, en tal caso, el hecho de que en ninguna de las memorias epigráficas aparecidas en las inmediaciones, se haga mención alguna de Baniana.

3 Aben-adhari, t. I. pág. 151 del texto arábigo; 273 y 274 de la trad. esp. de Fernández y González, ya citada.

4 “Descripción de África y España” pág. 205 del texto árabe, publ. por Dozy y De Goéje.

5 Madoz, Diccionario geográfico, tomo III, pág. 287. -Al-Maccari, t. I, págs. 103, 298, 49I de sus Analectas, texto árabigo, cita á Baena, "Bayena" como correspondiente al distrito de Córdoba, entre cuya ciudad y la villa había dos jornadas, mencionando a cierto Cásimben-Mohámma-ben-Yusuf-Abú-Mohámmad Al-Baeni, entre los hombres notables de Baena. 
Fuerza será, mientras no se disponga de más antecedentes, que nos contentemos con los conocidos, confensando que desde el siglo IX por lo menos, Baena existió con su nombre, y que durante el periodo de la dominación musulmana, aún después del Califato, fué población importante quizás en el concepto militar, deplorando que todavía el acaso no haya puesto de manifiesto en ella, según ocurre con los romanos, restos monumentales de la edad muslímica.

Rodrigo Amador de los Ríos

Madrid 13 de Marzo de 1897

El Defensor de Baena

\section{BIBLIOGRAFÍA}

ACIÉN ALMANSA, Manuel: (1984) "La formación y destrucción de Al-Andalus", Historia de los pueblos de España. Tierras fronterizas (I): Andalucía, Canarias. Barceló, M. (dir.). Argos Vergara. Barcelona. Pp. 21-55.

- (1989) "Poblamiento y fortificación en el sur de Al-Andalus. La formación de un país de Husun", Actas III Congreso de Arqueología Medieval Española. Madrid. Pp. I37-I 50.

- (1997) Entre el feudalismo y el Islam. 'Umar Ibn Hafsun en los historiadores, en las fuentes y en la historia. Universidad de Jaén. Jaén.

- (1998) "La desarticulación de la sociedad visigoda", Hispania, Al-Andalus, Castilla. Jornadas históricas del Alto Guadalquivir. Salvatierra Cuenca, V. (ed.). Jaén. Pp. 45-67.

- (1999) "Poblamiento indígena en Al-Andalus e indicios del primer poblamiento andalusl", Al-Qantara, XX, I. C.S.I.C. Madrid. Pp. 47-63.

AMADOR DE LOS RÍOS Y VILLALTA, Rodrigo: ( 1883 ) Memoria acerca de algunas inscripciones arábigas de España y Portugal.

- ( 3 de marzo, 1897) "Baena en los días de la dominación musulmana", El Defensor de Baena. Baena.

- (30 de diciembre, 1902) "Recuerdos de Baena (Córdoba). La parroquia de Santa María la Mayor", La llustración Española y Americana. Pp. 504-5 I 4.

- (1907) "Notas acerca de la batalla de Lucena y de la prisión de Boabdil en I483", Revista de Archivos, Bibliotecas y Museos, XVI. Pp. 36-66.

ARIZA ARMADA, Almudena: (junio 1993) "Un tesorillo de dirhemes de Baena (Córdoba)", Gaceta Numismática 109, I I. Asociación Numismática Española. Barcelona. Pp. 33-39.

ARJONA CASTRO, Antonio: (1978) "La cora de Cabra", Actas I Congreso Historia de Andalucía. Andalucía Medieval. Tomo I. Publicaciones del Monte de Piedad y Caja de Ahorros de Córdoba. Córdoba. Pp. 61-75.
- (1982) El reino de Córdoba durante la dominación musulmana. Córdoba.

- (1982) Anales de Córdoba musulmana (711-1008). Publicaciones del Monte de Piedad y Caja de Ahorros de Córdoba. Córdoba.

- (1983) "Nuevos datos históricos de Baena, Cabra y Priego en el siglo X", Córdoba en sus Cronistas. Retazos de Historia de la provincia. Caja Provincial de Ahorros de Córdoba. Córdoba. Pp. I53-I55.

BARCELÓ, Miguel: (1988, red. 1997) “¿Monedas lejanas? Nuevos indicios sobre la producción de monedas y la práctica administrativa fiscal durante el Califato omeya tardío", El sol que salió por occidente. Estudios sobre el estado Omeya en Al-Andalus. Universidad de Jaén. Jaén. Pp. 73-83.

BERNIER, Juan; SERRANO CARRILLO, Juan; MORENA LÓPEZ, José Antonio: (1984) Arqueología inédita de Córdoba y Jaén. Colección de Estudios Cordobeses, 35. Diputación Provincial de Córdoba. Córdoba.

CANTO GARCÍA, Alberto: (2002) "Moneda foránea en Al-Andalus", Actas X Congreso de Numismática Nacional. Albacete, 1998. Madrid. Pp. 107-128.

BARCELÓ, Miguel: Corpus de hallazgos de moneda musulmana en el territorio del antiguo Al-Andalus y regiones adyacentes. (e.p.)

CARDITO, Luz; MARTÍNEZ SALVADOR, Carmen; SEVILLA, Covadonga: (1993) "Hallazgo de moneda islámica en Baena", Córdoba, III Jarique de Numismática Hispano- Árabe. Madrid. Pp. 287-295.

CASTILLO ARMENTEROS, Juan Carlos: (1998) "El poblamiento islámico de la campiña de Jaén. La Época emiral y el tránsito a la califa)", Hispania, Al-Andalus, Castilla. Jornadas históricas del Alto Guadalquivir. Salvatierra Cuenca, V. (ed.). Jaén. Pp. 45-67.

CHALMETA, Pedro: (1994) Invasión e islamización: la sumisión de Hispania y la formación de Al-Andalus. Mapfre.

ESCUDERO ARANDA, José: (1987) "Excavación de urgencia en la muralla de la Almedina de Baena (Córdoba) en 1985", Anuario Arqueológico de Andalucía. Actividades de urgencia. Sevilla. Pp. I21 - 122.

GODOY DELGADO, Francisco: (199|) "Intervención arqueológica de urgencia en la Iglesia de Santa María la Mayor en Baena", Anuario Arqueológico de Andalucía. Actividades de urgencia, 1989. Sevilla. Pp. 127-133.

GUTIÉRREZ LLORET, Sonia: (1998) "Ciudades y conquista. El fin de las civitates visigodas y la génesis de las mudun islámicas del sureste de al-Andalus", Genése de la ville islamique en al-Andalus et au Maghreb occidental. Cressier, P. y García-Arenal, M. (eds.). Casa de VelázquezC.S.I.C. Madrid. Pp. 137-I57.

HUICI MIRANDA, Antonio: "Bayyana", Enciclopédie de I'Islam 2. Nouvelle Edition I A-B. Pp. I I 84.

IBN AL-KARDABUS: (1986) Historia de Al-Andalus. Maillo, F. (trad.). Akal. Madrid. 
LÉVI-PROVENCAL, Evariste: (1965) España musulmana. 7| I-103 I. Instituciones y arte. Historia de España dirigida por R. Menéndez Pidal. Tomo V. Madrid. 2' edición.

Libro de registro de entradas del Museo Arqueológico Provincial de Córdoba. (sin editar)

MADOZ, Pascual: (1987) "Baena”, Diccionario Geográficoestadístico-histórico de España y sus posesiones en Ultramar. Córdoba. Madrid -1948-50. Valladolid. Pp. 40-43.

MANZANO MORENO, Eduardo: (1993) "El asentamiento y la organización de los yund-s sirios en al-Andalus", AlQantara. Vol. XIV. 2. Madrid. Pp. 327-359.

MARCOS POUS, Alejandro; VICENT ZARAGOZA, Ana El': (1993) "Los tesorillos de moneda hispano-árabe del Museo Arqueológico de Córdoba", I I | Jarique de Numismática Hispano-Árabe, Madrid. Pp. 183-218.

MARTÍN ESCUDERO, Fátima (200 I): "El hallazgo omeya de Baena: un tesoro olvidado", Actas IV Jarique de Numismática Andalusí, Jaén. Pp. 8 I -94.

- (200I) "Tesoro de Baena", El esplendor de los Omeyas cordobeses. La civilización musulmana de Europa Occidental. Catálogo de piezas. 200 I. P. I I I.

- El tesoro de moneda omeya de Baena (Córdoba): una hipótesis sobre circulación monetaria. Memoria de Licenciatura dirigida por el Dr. Alberto Canto García. Facultad de Geografía e Historia. Departamento de Prehistoria y Arqueología. Universidad Autónoma de Madrid. Madrid. I tomo. Leída el 29 de junio de 2001.

MARTÍN GÓMEZ, Carmen: (200I) "Relieve decorativo mural", El esplendor de los Omeyas cordobeses. La civilización musulmana de Europa Occidental. Catálogo de piezas. P. 165.

MORENA LÓPEZ, José Antonio: ( 1989) El santuario ibérico de Torre paredones. Castro del Río-Baena. Córdoba. Estudios cordobeses. Publicaciones de la Excelentísima Diputación Provincial. Córdoba.
- (1990) "Prospección arqueológica superficial de urgencia en los terrenos afectados por el trazado de la variante de Baena (Córdoba)", Anuario Arqueológico de Andalucía. Actividades de urgencia. Sevilla, 1992. Pp. 78-82.

SÁNCHEZ DE LA ORDEN, Manuel; GARCÍA-FERRER PORRAS, A.: (1990) Prospecciones arqueológicas en la campiña de Córdoba. ETSIA. Córdoba.

NAVARRO OLTRA, Caries Vicent: (199|) "Troballa de dirhems califals a Baena (Córdova), anys 330-400 H.", Gaceta Numismática, I03. Pp. 7-I5.

PONS BOIGUES, Francisco: (1972) Los historiadores y geógrafos arábigo-españoles (800-I 450 A.D.). Philo Press. Amsterdam.

RUIZ QUINTANAR, Lourdes: La fragmentación de moneda en época omeya: el hallazgo califal de Haza del Carmen. Memoria de Licenciatura dirigida por el Dr.Alberto Canto García. Facultad de Geografía e Historia. Departamento de Prehistoria y Arqueología. Universidad Autónoma de Madrid. Madrid. Tomo I.

SALVATIERRA CUENCA, Vicente; SERRANO PEÑA, José Luis; PÉREZ MARTÍNEZ, Ma Carmen: (1998) "La formación de la ciudad en al-Andalus. Elementos para una nueva propuesta", Genése de la ville islamique en al-Andalus et au Maghreb occidental. Cressier, P. y García- Arenal, M. (eds.) Casa de Velázquez-CSIC. Madrid. Pp. I85-206.

SANTOS GENER, Samuel de los: (1956) "Monedas carolingias en un tesorillo de dirhemes del emirato cordobés", Numario Hispánico, V. Pp. 79-87.

VALLVÉ BERMEJO, Joaquín: (1986) La división territorial de la España musulmana. C.S.I.C. Departamento de Estudios Árabes. Madrid.

VALVERDE Y PERALES, Francisco: (1903) Historia de la villa de Baena. Toledo. 


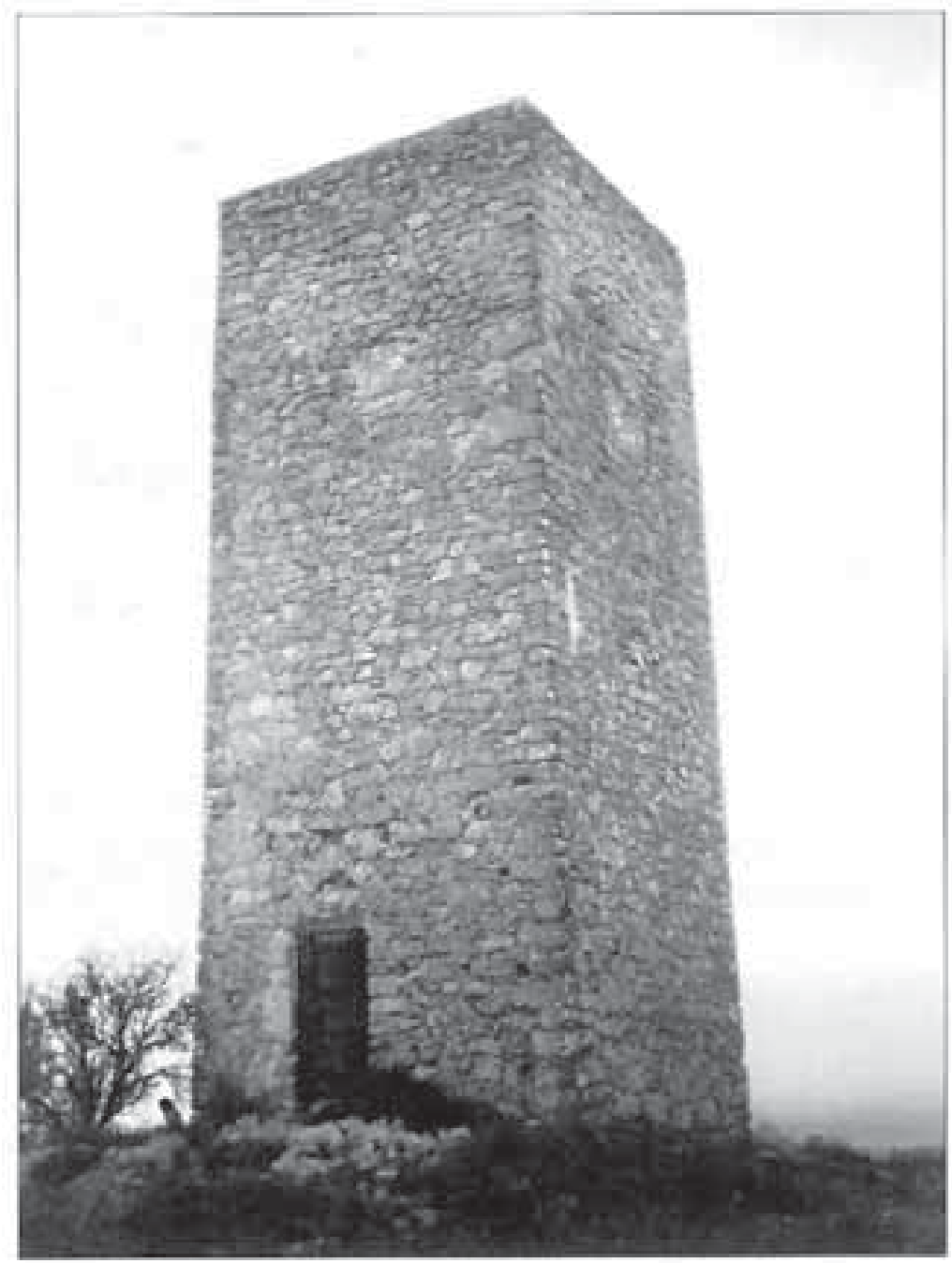

Fig. I. Ataliayd conocida camo

Torre del Montecillo o Torre

Manana.

Fig. 2. Vista de Boena con la torre corixch liamada "Torre del Sol"

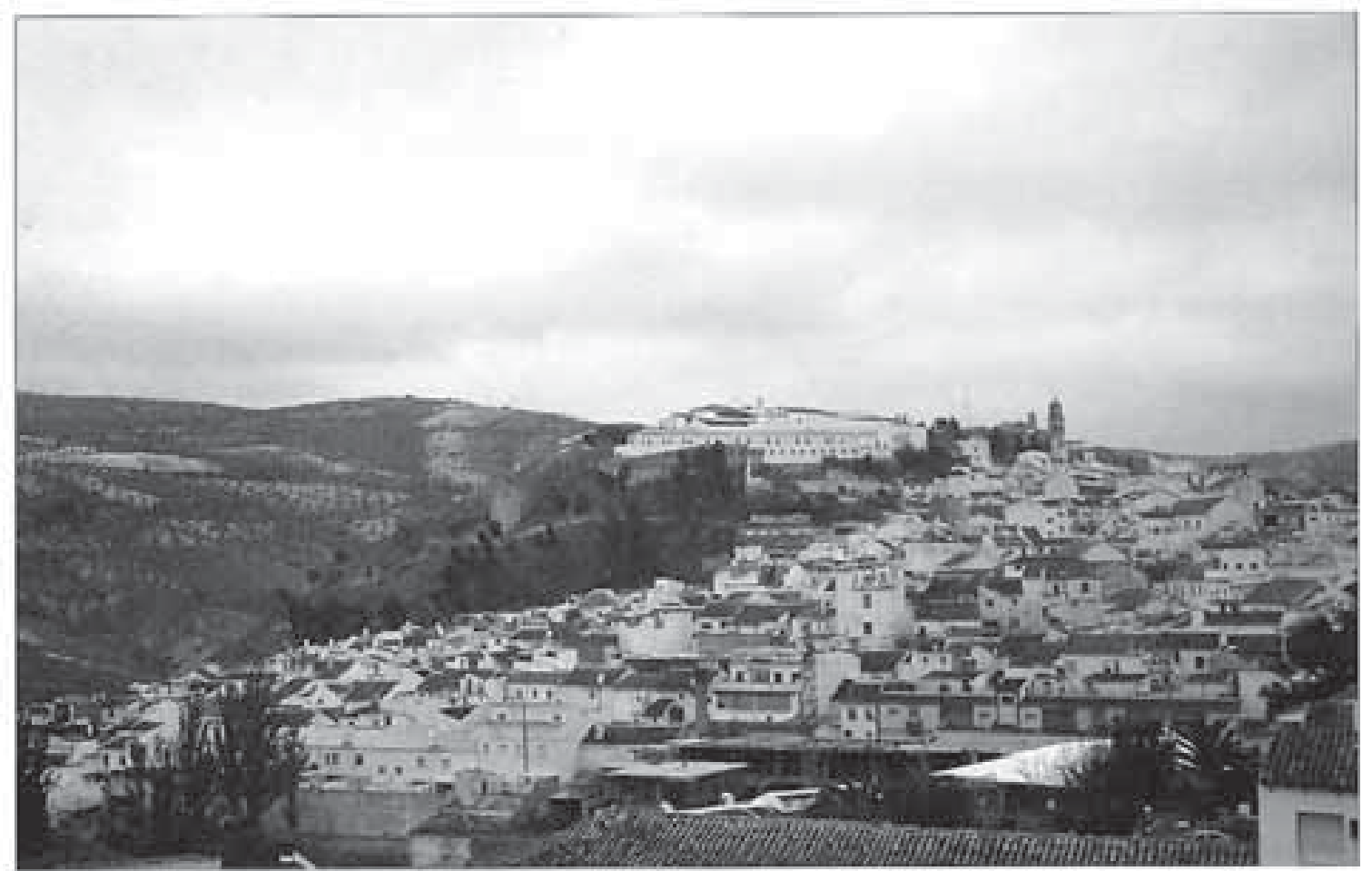


Fig. 3. Avco Consolación: puerta en recodo de cronologio almordvide.

Fig. 4. Anco Oscura puerta en recodo de cronología aimohode.
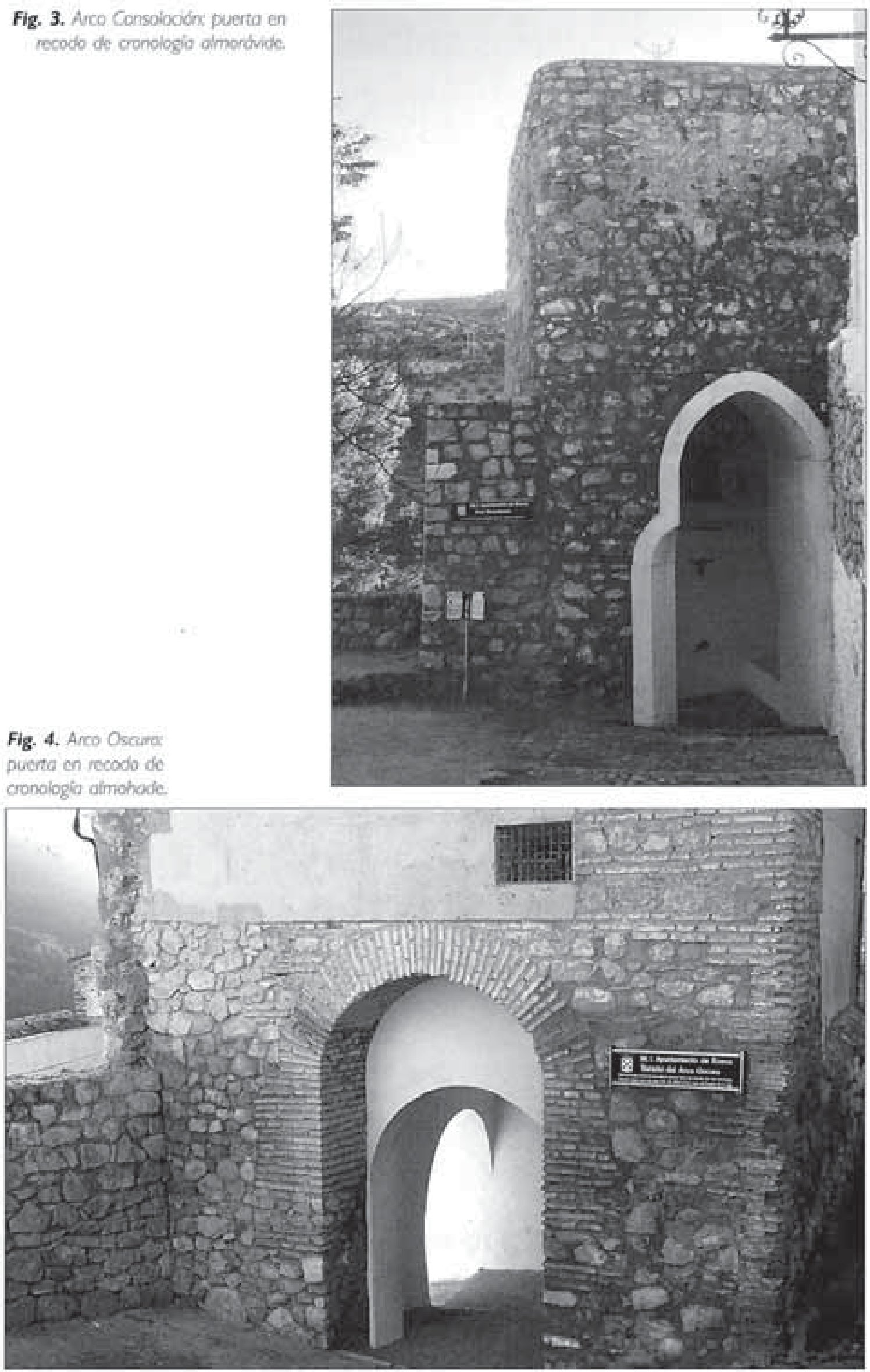